\title{
LA HISTORIA DE LAS IDEAS EN EL SIGLO XVIII: CONCEPCIONES ANTIGUAS Y REVISIONES NECESARIAS *
}

No tenemos el propósito de tratar tal o cual punto oscuro de la biografía o de la bibliografía de un ilustrado. Tampoco queremos considerar tal obra o tal acontecimiento particular, ni la influencia en el mundo hispánico de tal autor preciso, ni siquiera, en un plano más general, la de una corriente de pensamiento o de sensibilidad.

Nuestro proyecto, en su ambiciosa modestia, es el de renunciar a toda investigación erudita para abordar algunas grandes cuestiones, planteando problemas de método y proponiendo nuevas perspectivas, con el fin de suscitar un amplio debate entre los especialistas del siglo XVIII hispánico. Este empeño, que hubiera parecido presuntuoso hace unos quince años, está hoy en día grandemente facilitado por algunas revisiones - radicales a veces- a las que ha dado lugar recientemente la historiografía de la España ilustrada. Desde hace diez o quince años, nuestros conocimientos en este dominio han progresado considerablemente, pero lo más importante, en

* El BOCES,XVIII se honra publicando la ponencia presentada por el Prof. François López al IXe Congrès des hispanistes français de l'enseignement supérieur, celebrado en Dijon en 1973. La ponencia, publicada en forma mecanográfica en las Actas correspondientes, ha sido traducida, introduciendo algunas correcciones y las notas, por el propio autor. Las ideas del Prof. López son tan sugerentes y nos parece que abren tantos campos a la futura investigación dieciochista que creimos necesario incluirlas en nuestro Boletin. Algunos de sus puntos de vista se prestan a amplia discusión, y es posible que provoquen reacciones entre los estudiosos; pero ello será un indudable síntoma de que el panorama entrevisto no sólo es emocionante, en cuanto desconocido, sino que posee también un enorme poder de atracción. De cara al próximo II Simposio sobre el $P$. Feijoo y su siglo, en cuyo temario se incluye como punto primero el de "Concepto de la Ilustración españolas, este artículo puede ser un fructífero puntu de partida. 
verdad, es que ya no vemos del mismo modo lo que se conocía en el siglo pasado y en las primeras décadas del actual.

Para llegar sin más preámbulos a lo esencial, diremos que se empieza por fin a tomar clara conciencia de que los antiguos estudios dedicados al siglo XVIII español e hispanoamericano han padecido durante demasiado tiempo tres graves errores de enfoque:

1. ) Una mala periodización del progreso de las Luces.

2. ) La arraigada costumbre de privilegiar, en el orden socio-cultural, los cambios y las rupturas en detrimento de unas continuidades evidentes y de ciertos resurgimientos no menos manifiestos y de apasionante interés.

$3 .^{\circ}$ ) Una visión demasiado unitaria, demasiado monolítica de la Ilustración, que dejaba en la sombra las particularidades regionales y socio-económicas que determinaron constantemente ciertas actitudes y ciertas opciones ideológicas, cuya viva diversidad debe retener la atención del historiador, tanto por las supervivencias que traduce como por las eclosiones que anuncia.

Tales son los tres puntos que proporcionarán la materia de esta ponencia. Hablaremos pues, en primer lugar, de los problemas de periodización a los cuales se encuentra enfrentado inevitablemente todo historiador de la Ilustración.

La penetración en España y en el imperio español de la filosofia moderna fue muy lenta, mucho más lenta de lo que se ha venido pensando hasta estos áltimos años. Recientemente aún, se admitía que Feijoo se habia hecho el primer paladin de dicha filosolía, que gracias a él el racionalismo crítico y el método experimental se habian introducido de pronto en el pais, propagándose poeo a poco hasta las más remotas regiones de la América española y portuguesa. Así pues, pareeia muy legítimo originar en Feijoo y en su abra toda la renovación intelectual de la Ilustración. Esta, según se creía, empezaba a alborear en 1726, y el primer volumen del Teatro crítico eza el prehudio con el cual, más de treinta años antes del reinado de Carlos III, se abría el siglo XVIII español. Desgraciadamente acreditado por un historiador de las ciencias tan prestigioso como don Gregorio Marañón, este esquema. en verdat, era muy antiguo y correspondí fielmente a la imagen que cierta España ilustrada había querido dar de si misma. Ya podia 
encontrarse en las primeras páginas de la Biblioteca de los mejores escritores del reynado de Carlos III de Sempere y Guarinos. Este, por otra parte, exaltaba, como es de suponer, la dinastía reinante, sus constantes esfuerzos por proteger y fomentar las ciencias, las instituciones culturales de las que le era deudor el país. Ponderando encomiásticamente el gobierno de los Borbones, este cuadro, con ser tan a las claras tendencioso, ha llegado casi sin retoques hasta nosotros. De ello ha resultado que en nuestros estudios las décadas anteriores al Teatro crítico quedaban, hace poco aún, sin explorar. ¿De qué hubiera servido hacer alguin sondeo en aquella zona? Nada subsistía entonces del esplendor del Siglo de Oro; en cuanto a las Luees, quedaban todos persuadidos de que no empezaban antes de 1726. De modo que entre las tiltimas producciones de Caldexán y la aparición del Teatro crítico existía un extenso marjal incierto, desconocido, abandonado: medio siglo de oscuro caos y de indec miseria intelectual.

Ahora bien, en el espacio de unos pocos años, todo, al respecto, ha cambiado. Sabemos ahora, gracias a los trabajos de Ramón Ceñal, de Olga Quiroz-Martínez, de Vicente Peset y de José Maria López Piñero principalmente, que la filosofia y la ciencia modernas han penetrado en España a fines del sigrlo XVII, y que los primeros enfrentamientos entre escolásticos y novatores se produjeron mucho antes do que se publicara el Teatro crílico'. Reuniendo, coordinando, ampliando lo que las últimas investigaciones interdisciplinarias han puesto en claro, un excelente libro de López Piñero acaba de rasgar el velo que disimulaba a los historiadoros de ayer más de medio siglo de vida intelectual ${ }^{2}$. Lo primero que se encuentra en dicho libro es este texto muy significativo que el autor ha tomado por epigrafe:

"Que es hastimosa y aun vergonzasa cosa que. couno si fuéramos indiog, hayamos de ser los últimos en recilür las notictas y luees puiblieas que ya están esparcidas por Enropa. Y asimismo, que homber a quienes tocaba saber

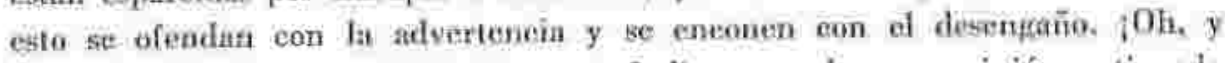
qué cierto es que el intentar apartar el dictamen de una opinión anticuada es de lo más difícil que se pretende en los hombres!

1 R. Ceñal, "Cartesianismo en España. Notas para su historia (1650-1750)\%, Revista te la Uninersidad de Oviedo, 1945, p. 5-97, 0. Quirca-Martinc\%, Let introdacoion de la filosefía moderna en Españo, Méxjeo, 1949; V. Peset, "La Universidad de Valencia y la renovación cientifica española (1687-1727)n, Asclepio, XVT, 1964; J. M. López Piñero, "Juan de Cabriada y las primeras etmpas de la iatroquimica y de la medieina moderma en Españan, Cuadernos de Historia de la Medietua Española, 1962, 2; ala Carta filoséfica. médieonedymica (1687) do Jual de Cabriala, punto de purtida de la medicina moderma en Esspaña, Asclepio, XVII, 1965.

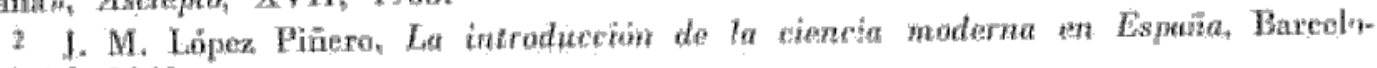
na, Ariel, 1969. 
¿Por qué para un fin tan santo, útil y provechoso como adelantar en el conocimiento de las cosas naturales (sólo se adelanta con los experimentos físico-químicos) no habían de hincar el hombro los señores y nobleza, pues esto no les importa a todos menos que las vidas... ;Oh, inadvertida noticia! Y si advertida, ¡oh, inútil flojedad!»

¿No se parece esto a una página del T'eatro crítico? Pues bien, estas líneas no son de Feijoo. Su autor es Juan de Cabriada, un joven médico que ejercía en Madrid bajo el reinado de Carlos II. La fecha de este texto: 1687. Como bien lo han puesto de relieve Vicente Peset y José María López Piñero, en este momento preciso es cuando se abre en España un primer frente contra el saber tradicional y la ciencia escolástica. En efecto, la Carta filosófica, médico-chymica de Cabriada no es la obra aislada de un hombre excepcional. Otros hechos no menos sintomáticos marcan el año 1687. Así es cómo, por ejemplo, otro médico cuya figura empieza a conocerse desde hace sólo unos años, Diego Mateo Zapata, llega por aquella misma época a Madrid y concurre a unas tertulias donde las nuevas doctrinas filosóficas son confrontadas y discutidas ${ }^{3}$. Además, estos círculos eruditos, el espíritu abierto que en ellos se manifiesta, no se encuentra tan sólo en la Corte. Algunas provincias conocen también estos primeros estremecimientos. En Zaragoza la voluntad de renovación se traduce por una reforma hospitaliaria que no tiene equivalente en España y por una floración de escritos médicos cuyos autores, Juan de Bercebal, Atilano Tomás Manente, Francisco Elcarte y sobre todo José Lucas Casalete, proclaman su adhesión a las modernas teorías iatroquímicas. En Valencia, donde la Facultad de Medicina se muestra más conservadora, el movimiento de las ideas afecta predominantemente a las matemáticas, la física y la astronomía. En Barcelona, donde existe desde 1675 un anfiteatro de anatomía, Joan d'Alós, sin dejar de afirmar su acatamiento a las tradicionales doctrinas galénicas, publica muy notables estudios de cardiología. Sevilla, por fin, que acoge más tardíamente la iatroquímica y la física experimental, es sin embargo la primera ciudad dotada de una institución científica resueltamente moderna: la Regia Sociedad de Medicina y otras Ciencias, fundada por Carlos II. Es pues en este momento cuando se anuncian verdaderamente las Luces. Mostrar que este despertar se produce mucho más temprano de lo que antes se suponía es admitir al mismo tiempo que no fue provocado por una causa externa, artificialmente suscitado por la política cultural de la nueva dinastía, sino que corresponde al movimiento general de la sociedad, que surge espontáneamente de este

3 El estudio más nutrido sobre Zapata es el de J. G. Merck Luengo, «La quimiatría en España), Archivo Iberoamericano de Historia de la Medicina y Antropología Médica, XI, 2, 1959. 
mismo movimiento. Es hacer constar, en suma, que el largo deshielo que precede a las Luces se manifiesta en el dominio socio-económico a la vez que en el socio-cultural. En efecto, como lo han subrayado los especialistas de la historia económica de España, a la altura de los años 80 del siglo XVII algo comienza a surgir, se inicia un virage: lo que Pierre Chaunu ha llamado un (tournant de sagesse». ¿,De qué se trata exactamente? En un libro ya antiguo, Albert Girard había sugerido que las opiniones corrientes sobre el reinado de Carlos II debían revisarse ${ }^{4}$. Posteriormente la historia de los precios en la península emprendida por Earl J. Hamilton, los estudios de demografía histórica de Jorge Nadal Oller y Emilio Giralt, los trabajos de José Fontana y Robert $\mathrm{S}$. Smith relativos a la industria catalana y al tráfico del puerto de Barcelona, por fin las admirables obras de Jaime Vicens Vives y de Pierre Vilar han contribuido a que numerosos historiadores abandonaran el punto de vista fundamentalmente político que había prevalecido hasta entonces y a que se pusiera a discusión la cronología de la Decadencia como también la del nuevo despertar de España. Así pues, se admite ahora corrientemente que las últimas décadas del reinado de Carlos II —del que cierta historiografía clásica sólo ha querido mostrar el aspecto más tenebroso y fantasmagórico- no fueron tan sombrías ni tan catastróficas como se ha creído durante tanto tiempo. Al contrario los signos de una estabilización, de un restablecimiento incluso, se perciben en algunas regiones y en ciertos sectores: la demografía, la industria textil, el comercio. "Hay que añadir, escribe Pierre Vilar, la muy importante indicación de Hamilton sobre los efectos de la muy dura pero necesaria operación monetaria de 1680 y de la ligera devaluación de 1686: condiciones de una estabilidad monetaria y de un movimiento de precios que, entre 1686 y 1714, hacen coincidir con los peores acontecimientos militares un tiempo de reposo y de recuperación para la economías ${ }^{5}$. En este contexto socio-económico, unos notables, preocupados ante todo por incrementar la producción y el comercio, son inducidos a definir nuevas necesidades, técnicas y cientificas. Feliu de la Penya en su Fénix de Cataluña no elude estos problemas. Pide una formación técnica para los pobres y los huérfanos con el fin de que se apliquen en iel trabajo, y, para una élite, una enseñanza teórica de más alto nivel. Preocupaciones del mismo orden se hacen patentes en otras partes, especialmente en Zarago-

4 A. Girard, Le commerce français à Séville et Cadix au temps des Habsbourgs: con tribution à l'étude du commerce étranger en Espagne au XVI et au XVII siècle, $\mathrm{Pa}$ rís, 1932.

5 P. Vilar, La Catalogne dans l’Espagne moderne, París, 1962, t. I, p. 671. 
za, ciudad manufacturera y comerciante. Ante la urgente necesidad de restaurar economías regionales y de echar los cimientos de una prosperidad futura, el tradicional divorcio entre la ciencia y la técnica tiende a abolirse. Ambas, dejando ya de oponerse, irán en adelante ayudándose y fecundándose. En esa época de transición es cuando aparecen los primeros novatores, cuyos conocimientos técnicos encuentran inmediata aplicación en ciertas tareas materiales y concretas. He aquí al P. José de Zaragoza, profesor en el Colegio Imperial de Madrid, eminente astrónomo y matemático, ocupado en varios trabajos hidráulicos y asuntos de minería, encargado además de es. tudiar el proyecto de construcción de un malecón en Sanlúcar. He aquí también a José Chafrión, discípulo del ilustre Caramuel, que dirige unas obras de fortificación en Cataluña y en el Milanesado, mientras otros valencianos como Juan Bautista Corachán, que en sus ratos de ocio empieza la traducción del Discurso del Método de Descartes, y Vicente Tosca, cuyos manuales de filosofía harán autoridad durante medio siglo, se convierten en ingenieros cuando se precisa reformar el puerto de su ciudad para que pueda acoger navíos de mayor tonelaje. $\mathrm{Y}$ no olvidemos que tareas técnicas muy parecidas le corresponden al primer novator de la América española, Carlos de Sigüenza y Góngora, encargado de inspeccionar los astilleros de Nueva España, gran admirador de Gasendo y autor de un tratado sobre los cometas, de un espíritu ya moderno. Por fin, en un momento en que se proyecta la creación de nuevas compañías de comercio, no es de extrañar que renazca la náutica, ilustrada por unas obras del gallego Francisco Seijas y Lobera, del vasco Antonio de Gaztañeta Iturrivalzaga, náutica que se convierte en materia de enseñanza en el Colegio de San Telmo, fundado en 1681. Física, matemáticas, cosmografía son hijas del comercio y la industria. Donde se ha mantenido la actividad mercantil, el sabio y el ingeniero asumen naturalmente el papel que les toca. "Cuando la sociedad tiene necesidades técnicas, decía Engels, la ciencia recibe más ayuda que la que podría recibir de diez universidades». No es pues ninguna casualidad si casi todos los novatores son valencianos, catalanes o aragoneses, ni si el único matemático realmente notable de la segunda mitad del siglo XVII español, Hugo de Omerique, mencionado con elogio por el mismo Newton, nació en una familia de comerciantes de Sanlúcar de Barrameda.

Pero volvamos a nuestro punto de partida, al texto ya citado de Juan de Cabriada:

"...Que es lastimosa y aun vergonzosa cosa que, como si fuéramos indios, hayamos de ser los últimos en recibir las noticias y luces públicas que ya estain esparcidas por Europa...” 
La comparación tan frecuente entre los arbitristas de las edades anteriores: “como si fuéramos indios», vuelve todavía bajo la pluma de este español inquieto. $\mathrm{Y}$ es que no puede hallar otra expresión más elocuente. Pero el mismo individuo habla ya de (luces públicas», deplorando que en el dominio del saber, de las ciencias exactas, España se haya puesto al margen de Europa. Todo, desde ahora, cobra otra dimensión. Lo que traducen estas quejas, no es ya sólo el marasmo de una economía, ni el malestar de una sociedad, sino la crisis de una civilización.

Todo esto nos lleva a plantear la cuestión del retraso socio-cultural de España respecto de los paises en que nacen las Luces: Inglaterra, Holanda, Francia. Con este objeto un método ha sido propuesto y puesto ya en olvra: como no pueden existiv la ideas fuera del lenguaje, esbozar la historia de. algunas palabras claves, fechar con la mayor precisión posible su aparicion y, para apreeiar su peneiración en profundidud, empozar por dislinguir varios niveles en el lenguaje escrito, del más minoritario al más común. Anticipándose a los resultados definitivos de ciertas investigaciones en curso. Pierre Chaunu nos propone a la vez los principios de dicho método y algumss conclusiones provisionales que, en nuestra opinión, resultan parcialmente inexactas. Veamos primero las reglas metodológicas, En los escritos examinados, el primer nivel (nivel 1) será el cle los tratados cientílicośs, de las obras de especialistas. El nivel 2, el de lo que llamamos hoy lía literatura (novelas, teatro, poesia, epístolas, etc.). El nivel 3, el de las correspondencias, es decir, el lenguaje escrito más corriente, el que acude espontáneamente bajo la pluma. Por fin el nivel 4 será lo que puede vislumbrarse a través de ciertos escritos del lenguaje usado por el pueblo. Ahora consideremos algunas paLabras claves, veamos en qué fecha aparecen en el mundo hispánico. Pierre Chaunu sigue un primer "convoy semánticon de las Luces y la Razón: filosofia, prejutcio, supersticion, tolerancia, vitrtud. Nociones todas que caracterizan la filosofía militante, palabras que comenta Voltaire en su Dictionnaire philosophique, y a las cuales conviene añadir las de: abuso, reforma, abusivo, reformar, constitucion, liberlades, vasallo y ciudadmo en su tensión complementaria, libertad, igualdud, derechos, "El equivalente, dice Pierre Chaunu, existe en los diez idiomas escritos de Europa... El convoy se mueve desde el oeste hacia el este, y desde el norte hacia el sur. El nivel 1 se alcanza hacia 1700 en tal país, hacia 1710 eñ tal otro y llega a su punto de saturación hacia $1720 \ldots$ España está en el nivel 1 hacia, 1730 , en el 2 tan sólo hacia 1750 ; ${ }^{\circ}$. Estas conclusiones, como hemos dicho, son pro-

6 P. Chaunu, La civilisation de l'Europe des Lumières, Paris, Arthaud, 1971, p. 20.21. 
visionales y anticipadas. Aun siendo asi, conviene discutirlas oponiéndole ya un primer reparo: el «convoy semánticon ya señalado no penetra en España de una vez, ni mucho menos. En la fecha avanzada, es decir en 1720 , hemos encontrado únieamente en los escritos que hemos mancjado: preockpado, preocupación, superstición (palabra usada pocas veces y con mucho tiento), abuso y reforma. Todas estas palabras son del vocabulario de Feijoo, es decir que hacia 1730 el nivel I está ya sobrepasado puesto que el Teatro crítico es una obra de vulgarización. Pero hay que advertir que estos términos siempre se encuentran en un contexto bien definido, restringido: cuando se trata de las disputas escolásticas y de una deseable reforma de los estu. dios. Fuera de la filosolia de las eseuclas (la cual ya es mucho), nada fundamental se halla atacado. Una palabra tan importante como tolerancia, con su familia léxica: tolerar, tolerante, intolerancuta, intolerante, tolerantismo no ha de cobrar un sentido politico-religioso sino mucho más tarde, en las ültimas décadas del siglo?. Virtud conserva su tradicional acepeión religiosa hasta Ios an̄os 1760-1770. En cuanto al vocabulario politico: constituciún, ciudadano, libertad, igualdad, derechos, sólo forma constelación, en los niveles 1,2 y 3 , cuando la Ilustración, bajo el reinado de Carlos III, está en su apogeo.

Esta primera aproximación lexicológica, entre otras eonsideraciones, nos incita a proponer toda una periodización de las Luces que podría dar materia a un amplio debate. A Ios primeros estremecimientos, a la puesta en acusación de la eiencia y la filosofía tradicionales, se pueden asignar unos cuarenta años, interrumpidos por una larga guerra civil, el período que va desde 1680 hasta 1720 poco más o menos. Después, las nociones y los métodos introducidos por los novatores son progresivamente divulgados por el Teatro aritico, las Cartas eruditas, por otras olsras que se mantienen en la línea del movimiento novator, por una serie de tradueciones y por una incipiente prensa periódica. Esta es, por excelencia, la época de Feijoo, que va desde 1726 hasta 1760 aproximadamente. Poco a poco va difundiéndose la nueva filosofia, y una élite ilustrada comienza a constituirse. Estos dos periodos, cada uno de los cuales liene una duración de unos cuarenta años, representan en España y, con mucho retraso, en Hispanoamériea, el primer periodo de expansión de la revolución mecanicista y del racionalismo cuítico. Las palabras claves de esta época son: filosofia experimental, o escéptica, o ecléctica, razón y su imprescindible complemento experiencia, experimentos, crítica, sistema, fenómeno, y los sinónimos adelantos, aumentos, progresos.

7 R. Lapesa, "Ideas y palabras: del vocabulario de la Ilustración al de los primeros liberales", Asclepio, XVII-XIX, 1966-1967. 
Luego llega el reinado de Carlos III, de 1759 a 1788: la Ilustración propiamente dicha. El Siglo de las Luces, durante tanto tiempo aplazado, ha encontrado por fin su derrotero y tomado su curso. Todo se pone ya en movimiento. Unas energías acumuladas desde hace tiempo van liberándose. La minoría ilustrada se acrecienta notablemente, y pueden distinguirse en el espacio de este gran reinado dos generaciones de autores cuyas producciones son presentadas a Europa por Scmpere y Guarinos en su Biblioteca... Todo se acelera, las ideas se propagan con mucha más rapidez que antes, y las grandes nociones de este tiempo, que invaden casi simultáneamente los niveles 1, 2 y 3 son: Filosofía y Filósofo ( $\sin$ ningún adjelivo ya), ilustrar, ilustración, Género humano, Humanidad, bien público, bien común, provecho comín, patriota, patriotismo, patriótico, laborioso, ciudadano, virtud (la virtud laica del buen ciudadano), constitución, libertad.

Después de esta «belle époque», las Luces sufren una crisis duradera. La Revolución francesa, que interesa primero y pronto infunde miedo, coloca a los ilustrados más audaces en mala postura. Además la fe que se ponia en ciertas grandes iniciativas gubernamentales y en la eficacia de una minoría emprendedora e ilustrada conoce también una crisis. Pero si los reaccionarios sacan amplias ventajas de la coyuntura, la historia y las ideas no se detienen. Los acontecimientos de Francia ponen en boga, incluso en el pueblo bajo de las ciudades, nuevas palabras, y los reformadores, por su parte, viven obsesionados por In anarquia, el desporismo, la servidumbre, la tiranía. También tratan a menudo en sus escritos de convenio y de pacto social. Algunos años más tarde hablarán de leyes fundamentales, de asamblea general y de representantes: están convocadas las Cortes. A fines de 1810 estalla el conflicto entre liberales y serviles, en espera del restablecimiento del absolutismo y del lamentable siglo XIX de los guerrilleros, de las camarillas, de los pronunciamientos, de los moderados y los exaltados.

Es la última etapa de las Luces que se sobreviven hasta nuestro tiempo en algunas nociones fundamentales como civilisación (en singular: la civilizaeión, que suele oponerse a la barbarie), progreso, educación, ete. Luces todavía actuales, siempre renacientes, que forman parte de nuestro patrimonio intelectual y que siguen alimentando en Europa y otros continentes mitos, proyectos, actos, constituyendo el programa de muchas naciones jovenes resueltas a enfrentarse al problema de los desniveles sociales y culturales, de las mentalidades arcaicas, del subdesarrollo económico y tecnológico.

Ateniéndonos a España e Hispanoamérica, que las ideas y las nociones de las Luces subsisten a lo largo de todo el siglo XIX, es un hecho comprobado por una abundante literatura militante, centrada en la oposición dua- 
lista civilización-barbarie. Véanse, para América, las obras de Sarmiento y todavía las de Rómulo Gallegos.

Pasemos ahora al segundo punto. Después de hablar muy generalmente de cambio y de evolución, consideremos las continuidades y los resurgimientos que no tienen menos importancia para una buena inteligencia del siglo XVIII español. La historiografía de las Luces - siempre hay que recordarlo - ha nacido en una época de crisis, de luchas intestinas, de guerra civil. Desde el principio ha sido apasionada, comprometida, sectaria. Los liberales sólo han querido ver en la Ilustración lo que anunciaba su liberalismo. Los tradicionalistas, por su parte, han dado en representar el Siglo de las Luces como una época de imitación servil, de rastrera adulteración, de traición respecto a algunos valores declarados específicamente nacionales. Todo esto ha conspirado a imponer durablemente la imagen de un siglo desvinculado de toda tradición patria, sin amarras en el pasado español, de una época de deliberada ruptura. Y como el siglo XVIII francés fue un siglo revolucionario, muchos estudiosos han caído en la tentación de considerar bajo el mismo enfoque el XVIII español, proyectando sobre España cierta concepción de las Luces que fue la de un Michelet y que éste, seguido todavía por no pocos historiadores, resumía de este modo con su inimitable estilo:

"Un niño nacido sin padre», he aquí el nombre del siglo XVIII, su singular privilegio.

Siente asco, náuseas, horror por cuanto se refiere al siglo XVII. Con toda certidumbre, dicho siglo no le aporta nada.

Del gran siglo XVI, no conoce absolutamente nada. Ignora de un modo asombroso su parenteseo con Montaigne y Rabelais, con el libre Renacimienton.

Este juicio somero, que ya es discutible por lo que toca a Francia, en ningún modo puede aplicarse al caso español. Una de las tareas fundamentales que se asignó la Ilustración fue precisamente la sistemática exploración de España, de su espacio, de sus recursos, de sus mentalidades, de su pasado. Los más eminentes ilustrados, Campomanes, Capmany, Jovellanos, Forner, han sido todos, quien más, quien menos, historiadores. Hasta Cadalso, que nada tenía de erudito y sólo pretendía ser un hombre de bien, afirmó vigorosamente que nadie pocía presumir de conocer un país sin enterarse primero de su historia, idea fecunda y para aquellos tiempos muy nueva. Más 
tarde, en las Cortes de Cádiz, pudieron reconocerse los liberales no sólo por sus ideas reformadoras sino también por su buen conocimiento del pasado nacional.

No, en verdad, el siglo XVIII español no ignoró las edades que le habían precedido. Hay que confesar por cierto que los ilustrados renegaron del siglo XVII. En su opinión aquélla era la época en que España se había descarriado, poniéndose al margen de Europa, por culpa sobre todo de su mal gobierno y de las clases dominantes. También es cierto que sintieron por la literatura y el arte barrocos, que se habían impuesto en aquel entonces, una invencible repulsión, podemos decir incluso un odio visceral. Pero era porque dicho arte, dicha literatura habían expresado $-\mathrm{y}$ ellos lo barruntaban indudablemente - unas relaciones sociales arcaicas y por lo tanto, a su ver, escandalosas y odiosas. A pesar de tcdo, ese arte y esa literatura habían de sobrevivir, a despecho de las condenas fulminadas por la minoría ilustrada. Ahora bien, ¿quién se ha propuesto estudiar estas permanencias, la fortuna en la España de las Luces de la novela cortesana, de las novelas picarescas, de algunos libros de caballerías todavía editados, del teatro de Calderón y de sus epígonos, más generalmente de las comedias del Siglo de Oro reeditadas a lo largo de todo el siglo XVIII en volúmenes y en innumerables pliegos sueltos? René Andioc nos ha mostrado con meridiana claridad que en tiempos de Moratín el público de los teatros madrileños prefería a las obras de Calderón las comedias de magia y otras obras por el estilo $^{8}$. Pero ¿quién se ha ha interesado por esas comedias sueltas que se leian entonces como hoy se leen las novelas de gran difusión, y de las que algunos extractos pasaban a veces al romancero vulgar? ${ }^{9}$. Por lo que toca a la literatura, a lo que hoy designamos con esta palabra, el estudio de las continuidades, de las permanencias está todavía por hacer. Y mientras no se emprenda, estemos persuadidos de que no acabaremos de conocer el verdadero semblante del siglo XVIII español.

También hemos hablado, al principio de esta ponencia, de resurgimientos. Como es éste un tema que nos ha interesado particularmente, podemos afirmar que no hay un solo dominio del pensamiento ilustrado en que ciertos resurgimientos de ideas o de corrientes ideológicas muy antiguas no estén abundantemente atestiguados. Así es como en el dominio de las ciencias los novatores muestran un perfecto conocimiento de Ios escritos de Vives,

8 R. Andioc, Sur la querelle du théâtre au temps de Leandro Fernández de Moratín, Bordeaux, 1970.

9 Sobre los «romances de comedia», véase el libro de J. Caro Baroja, Ensayo sobre la literatura de cordel, Madrid, 1969, p. 182. 
Gómez Pereira, Sabuco de Nantes, Huarte de San Juan, Simón Abril, que les parecen todavía tan actuales que los hacen reeditar.

En el dominio de la reflexión política, económica y social, los hombres de la Ilustración jamás han olvidado que en las horas más sombrías de la Decadencia algunos espíritus lúcidos y sagaces habían formulado excelentes diagnósticos respecto a los numerosos males que agobian al país. Han tributado sentidos homenajes a la perspicacia de Pedro de Valencia, Tomás de Mercado, Sancho de Moncada, Pedro Fernández de Navarrete, Mateo Lisón de Biedma, Francisco Martínez de la Mata, Juan de Arrieta, Miguel Caja de Leruela, Diego de Saavedra Fajardo, Eugenio de Narbona, etc. Y muchas veces han vuelto a dar a luz las obras de estos autores.

En lo que se refiere a la literatura, admirables eruditos se han afanado en colocar a Cervantes en el rango que le correspondía y en sacar de un secular olvido las poesías de fray Luis de León, Garcilaso, Herrera, y otros vates que habían dado a España su edad clásica. Mayáns, Cerdá y Rico, Sánchez han exhumado numerosos escritos de los siglos XVII, XVI y de la Edad Media, dedicando una labor inmensa y fecunda a la reconstitución de todo el patrimonio cultural de la nación.

En lo que atañe a la espiritualidad, a las ideas religiosas, no se ha subrayado bastante lo que debían los españoles ilustrados a los erasmistas, Vives, Vergara, Furió Ceriol, Luis de Granada, Venegas, Avila, etc. ${ }^{10}$. Generalmente no se ha destacado suficientemente hasta qué punto la España de las Luces ha sido solidaria del libre siglo XVI y cuán profundamente ha tomado conciencia de dicha solidaridad histórica. Recordemos que el siglo XVIII en España se abre y se acaba con dos grandes debates que pueden parecer curiosamente anacrónicos en la época de Montesquieu, Voltaire y Rousseau, dos debates que tienen que ver a la vez con la historia de la lengua y con la de las mentalidades religiosas. El primero ha agitado toda la primera mitad del siglo, prolongándose incluso en la segunda. La cuestión que se planteaba era la de saber si era o no lícito tratar de las graves materias filosóficas y científicas en castellano. Los novatores, oponiéndose a los escolásticos, no pudieron por menos de acudir en estas circunstancias a muy antiguos argumentos, que ya emplearan los humanistas del Renacimiento. El segundo debate parece atañer exclusivamente a la historia religiosa pero mantiene sin embargo alguna relación con el dominio

10 Véanse sin embargo los trabajos de A. Mestre, Ilustración y reforma de la Iglesia. Pensamiento político-religioso de Don Gregorio Mayáns y Siscar (1699-1781), Valencia, 1968, y de M. Giovanna Tomsich, El jansenismo en España, Madrid, 1972. 
lingüístico. Se trata de la polémica sobre la traducción de las Sagradas Escrituras al idioma vulgar. Joaquín Lorenzo de Villanueva se hizo con elocuencia y autoridad el paladín de esta muy antigua causa en que fueran derrotados los erasmistas dos siglos antes, y el aparato erudito en que fundamentó su alegación muestra una sorprendente y reveladora familiaridad con la literatura espiritual del siglo XVI, particularmente con la que se reclamaba de la Paraclesis de Erasmo. Eminentes antecesores le habían dejado al respecto una vía ya trazada: Mayáns, Pérez Bayer, Pellicer, Cerdá y Rico.

No, repitámoslo, el Siglo de las Luces no fue en España un "niño nacido sin padre». Tuvo claro conocimiento de su parentesco con el siglo XVI, cuya herencia recogió piadosamente. La Contrarreforma había podido aplazar durante largo tiempo lo inevitable, pero los problemas que no había hecho más que eludir se plantearon otra vez a los españoles de la Ilustración que jamás hicieron tabla rasa del pasado y estuvieron buscando en él constantemente modelos, ejemplos, incitaciones a la acción, retrospectivas justificaciones de sus proyectos. Tanto es así, por otra parte, que la noción de Siglo de Oro, con todo lo que lleva entrañando de respeto, de admiración y de orgullo nació precisamente al alborear las luces. Después, los liberales de las Cortes de Cádiz conocieron suficientemente la historia de su país para honrar la memoria de los erasmistas españoles perseguidos, en los que legítimamente podian encontrar remotos antecesores espirituales.

Es hora, pues, de acabar de una vez con la rencorosa leyenda del «siglo afrancesado» y de ver cuántas amarras enlazan dicho siglo con las épocas anteriores, amarras que algunos han querido ignorar para mejor desfigurar y desacreditar las Luces españolas.

\section{III}

Terminemos, como lo hemos anunciado, sugiriendo que la representación de las Luces elaborada por la historiografía tradicional ha sido demasiado unitaria, demasiado monolítica; y lamentando que esta concepción que nos parece falsa y superficial encuentre todavía muchos partidarios. La Ilustración, a nuestro parecer, no fue, ni mucho menos, una filosofía única, perfectamente homogénea, sino la convergencia momentánea, provisional, de ciertas tendencias ideológicas distintas y en algunos puntos opuestas. Si todos los ilustrados han tomado a pecho combatir las mentalidades arcaicas, sustituyendo la razón a la costumbre, devolver al país la prosperi- 
dad y el poderío que poseyera antaño, también es de notar que han propuesto para ello, según los grupos de presión y los sectores sociales que representaban, vías y medios que discordaban a menudo notablemente. Por ejemplo distaban mucho de estar de acuerdo sobre unas cuestiones tan fundamentales como la misión del Estado, sobre la utilidad de sus intervenciones en todos los dominios, los beneficios y los inconvenientes de la centralización administrativa y jurídica proyectada por los Borbones. Algunos encomiaron el individualismo y la libre empresa. Otros fueron partidarios hasta el último extremo del intervencionismo y el dirigismo. Algunos han hecho el elogio del lujo y defendido los gastos suntuarios, mientras que otros aspiraban a una austeridad espartana. Pensamos, pues, que conviene otorgar la mayor importancia a estas discrepancias ideológicas, sin perder de vista en ningún momento que fueron determinadas por intereses diferentes, por realidades socio-económicas y regionales muy diversas. Para ilustrar la oposición de tendencias de la que hemos hablado, tomaremos un ejemplo que todos los dieciochistas conocen desde hace tiempo: la divergencia radical, ya subrayada por Joaquín Costa, que se manifiesta entre las tesis expuestas por Jovellanos en su Informe sobre la ley agraria y los pareceres y dictámenes de numerosas personalidades consultadas al respecto, dictámenes de los cuales Jovellanos, en principio, debía hacer una sintesis y sacar conclusiones. Podríamos evocar otras muchas discrepancias que no han llamado tanto la atención, pudiendo dar materia a útiles reflexiones. Tomemos un caso preciso: Antonio Elorza en su reciente libro sobre La ideología liberal en la Ilustración española confiesa con perfecta honradez que los motivos de ciertas contradicciones le parecen inexplicables. A propósito de Capmany, he aquí lo que escribe: "(Capmany) ... publica en 1778 con el seudónimo de Miguel de Palacios, un discurso en defensa de los gremios, siguiendo las líneas del que doce años antes redactara con idéntico objeto Romá y Rosell. No se ve bien, sin embargo, cómo su relación con los burgueses de la Junta de Comercio pudo coordinarse con su apología de los retrógrados gremios, que hasta fin de siglo no aparecen en conexión amistosa con ella». He aquí una típica ocasión en que un historiador que conoce muy bien el siglo XVIII topa con una dificultad a primera vista insuperable. ¿Será que la ideología de Capmany, en el momento en que redacta su discurso, carezca de coherencia y lógica? No lo creemos y, a nuestro entender, Antonio Elorza no concede bastante importancia al hecho de que Capmany no representa cualquiera burguesía sino unos grupos específicamente catalanes. Que el otro defensor de los gremios mencionado por Antonio Elorza, Romá y Rosell, sea también catalán, es un indicio que no podemos pasar por alto. Además no estamos totalmente convencidos de que los 
alegatos de un Romá o de un Capmany en favor de los gremios puedan ser considerados como retrógrados o ilógicos. El lector de las Memorias históricas de Barcelona podrá incluso encontrar en semejantes alegatos la expresión de unos sentimientos muy democráticos.

De todos modos conviene tener presente cuando se estudia el siglo XVIII este hecho fundamental: la España de la Ilustración no es una nación bien soldada, y sería más exacto hablar de las Españas Ilustradas que de una España de las Luces. Un ilustrado catalán no ve las cosas del mismo modo que un valenciano, un aragonés, un vasco o un castellano. Esto es evidente y con ello no pretendemos decir nada nuevo. Algunos historiadores, como Carmelo Viñas y Mey, han afirmado que España en el siglo XVIII alcanzaba por vez primera la unidad nacional en el orden político y en el espiritual. Por otra parte, ha mostrado José Antonio Maravall que el moderno concepto de «nación» se forjaba en las últimas décadas de esa centuria. Es cierto y no es cierto. Queremos decir que la evolución hacia la unidad nacional no se ha cumplido totalmente durante la Ilustración y que, si bien se hablaba en numerosos textos de "la nación española», permanecía vivo y profundamente arraigado el sentimiento de que existía una «nación catalana», una (nación aragonesa», una ("nación vascongada». Además estos antagonismos entre provineias han subsistido a lo largo de todo el XVIII, y no sólo de un modo latente, porque ocurrió en ciertas ocasiones que unas tensiones se manifestaran abiertamente como en el muy notable Memorial de Greuges, revelado hace poco por Enric Moreu-Rey ${ }^{11}$, que viene a ser nada menos que un (cahier de doléances» redactado por los diputados de la antigua Corona de Aragón en 1760. En las provincias que habian sido autónomas, en las que conservaron su autonomía, el apego a los fueros, la conciencia de un destino histórico y de una psicología colectiva fraguada durante siglos y profundamente distinta de la mentalidad y del destino de Castilla, jamás desaparecieron. Véase sobre esto el excelente libro de An. tonio Mestre: Historia, fueros y actitudes políticas. Mayáns y la historiografía del XVIII; véanse por fin las páginas importantísimas con que empieza la tercera parte de las Memorias históricas de Barcelona de Capmany, en que se levanta acta del fracaso de la política ilustrada y se expresa la toma de conciencia de unas diferencias irreductibles entre Castilla y la (comunidad nacional» (dice Capmany) que forman los catalanes.

Para volver a la historia de las ideas, digamos que los estudios que se han publicado hasta estos últimos años sobre la España ilustrada han sido

11 E. Moreu-Rey, El «Memorial de Greuges» del 1760, Barcelona, 1968. 
demasiado particulares o demasiado generales. No se ha tomado suficientemente en cuenta que la buena historia de las ideas, siempre dispuesta a integrarse en un estudio más amplio de las mentalidades, tiene que hacerse, sobre todo tratándose de España, en un cuadro regional, teniendo en cuenta además la estratificación socio-económica, las disparidades culturales, la herencia histórica de cada provincia. Nos hace falta una buena historia de la vida intelectual en Aragón, desde la época de Diego José Dormer hasta la de Ignacio de Asso, y esperamos todavía que unos estudios que tomen por límites cronológicos los del período 1680-1780 se dediquen al País Vasco, a Cataluña (aquí todo será más fácil, ya que podrán los investigadores disponer de un trabajo magistral sobre las infraestructuras económicas), sobre el reino de Valencia por fin, aunque aquí el trabajo ha sido ya emprendido magníficamente por Antonio Mestre, Vicente Peset, Sebastián García Martínez y otros.

Todo esto lo podrían realizar equipos de investigadores que colaborasen estrechamente y estuviesen determinados a reconstituir para cada región de España, para cada provincia de la América española, todo lo que alimentó los mitos, las creencias, las ideologías de las minorías ilustradas y también de las masas populares. Las encuestas venideras tendrán que explorar todos los escritos de la Ilustración, desde el voluminoso curso de teología, escrito en latín, hasta los humildes pliegos de cordel. Deberían incluso ir más allá de los ecritos para tratar de alcanzar la literatura oral, la cultura popular.

Todo o casi todo en estos dominios queda por hacer y las investigaciones, indudablemente, serán difíciles y delicadas. Pero la comprensión de todo un siglo que ha sido durante tanto tiempo vilipendiado y mal conocido justifica estos empeños.

Además las grandes crisis del siglo XIX, sus luchas intestinas, podrán explicarse mejor. Se advertirá más claramente que la Renaixença catalana, por ejemplo, estaba ya germinando en el siglo XVIII, y también quizás los conflictos que han desgarrado a la España del norte y del nordeste. Así, habiendo mostrado lo que el siglo XVIII debe a los anteriores, y los problemas, las contradicciones futuras que anuncia ya, podremos tener la certeza de haber cumplido, concienzudamente, con nuestro deber de historiadores.

François Lopez

Universidad de Burdeos 